\title{
Manganese Catalysed Dehydrogenative Synthesis of Urea Deriva- tives and Polyureas
}

\author{
Aniekan Ekpenyong Owen, Annika Preiss, ${ }^{\dagger}$ Angus McLuskie, ${ }^{+}$Chang Gao, + Gavin Peters, Michael \\ Bühl,* Amit Kumar*
}

School of Chemistry, University of St. Andrews, North Haugh, St. Andrews, KY169ST.

KEYWORDS. Catalysis, Dehydrogenation, Manganese, Methanol, Pincer, Polyurea, Urea.

\begin{abstract}
Urea derivatives are prevalent intermediates in the synthesis of resin precursors, dyes, agrochemicals, and pharmaceutical drugs. Furthermore, polyureas are useful plastics with applications in coating, adhesive, and biomedical industries and have a current annual market of USD 885 million. However, the conventional methods for the synthesis of urea derivatives and polyureas involve toxic reagents such as (di)isocyanates, phosgene, $\mathrm{CO}$, and azides. We present here the synthesis of (poly)ureas using much less toxic reagents - (di)amines, and methanol via a catalytic dehydrogenative coupling process. The reaction is catalyzed by a pincer complex of an earth-abundant metal, manganese, and liberates $\mathrm{H}_{2}$ gas, valuable by itself, as the only by-product making the overall process atom-economic, and sustainable. A broad variety of symmetrical, and unsymmetrical urea derivatives and polyureas have been synthesized in moderate to quantitative yields using this catalytic protocol. Mechanistic insights have also been provided using experiments and DFT computation suggesting that the reaction proceeds via an isocyanate intermediate.
\end{abstract}

\section{INTRODUCTION}

Urea derivatives are prevalent organic compounds with a variety of applications such as resin precursors, ${ }^{1}$ dyes, ${ }^{2}$ agrochemicals, ${ }^{3,4}$ pharmaceutical drugs, ${ }^{5,6}$ and in supramolecular chemistry. ${ }^{7}$ Additionally, polyureas are useful classes of plastics with a range of applications for construction materials (e.g. coatings, adhesives), ${ }^{8}$ and biomedical industry (e.g. drug delivery). ${ }^{9}$ The current industrial methods for the synthesis of urea derivatives or polyureas involve reaction of amines or diamines with highly toxic reagents such as phosgene, ${ }^{10}$ (di)isocyanates ${ }^{11}$ or CO. ${ }^{12}$ Reaction of $\mathrm{CO}_{2}$ with (di)amines for the synthesis of (poly)ureas have also been reported but they suffer from drawbacks such as the use of harsh reaction conditions (e.g. temperature $>150{ }^{\circ} \mathrm{C}$, pressure $>40$ bar), and limited substrate scope. ${ }^{13-16}$ Thus, the development of an atom-economic, safer, and sustainable route for the synthesis of (poly)ureas will be highly valuable to chemical industries and benefit human health, and the environment.

Reactions based on catalytic dehydrogenative coupling are green and atom-economic routes for the synthesis of organic compounds. ${ }^{17,18}$ Several carbonyl compounds such as ketones, esters, and amides, along with polymers such as polyesters, ${ }^{19}$ and polyamides ${ }^{20,21}$ can be synthesized using the approach of acceptorless catalytic dehydrogenative coupling of alcohols and amines. ${ }^{22-25}$ This approach has also been utilized for the synthesis of urea derivatives via the dehydrogenative coupling of amines and methanol. The first example of the synthesis of urea derivatives from the dehydrogenative coupling of amines and methanol was reported by Hong using a ruthenium-Macho-BH pincer catalyst (A, Figure 1). ${ }^{26}$ A TON of up to 190 was reported for the synthesis of symmetrical ureas, however, the synthesis of unsymmetrical ureas was achieved using a complex two-step method and higher catalytic loading $(\mathrm{TON}<15)$. Additionally,

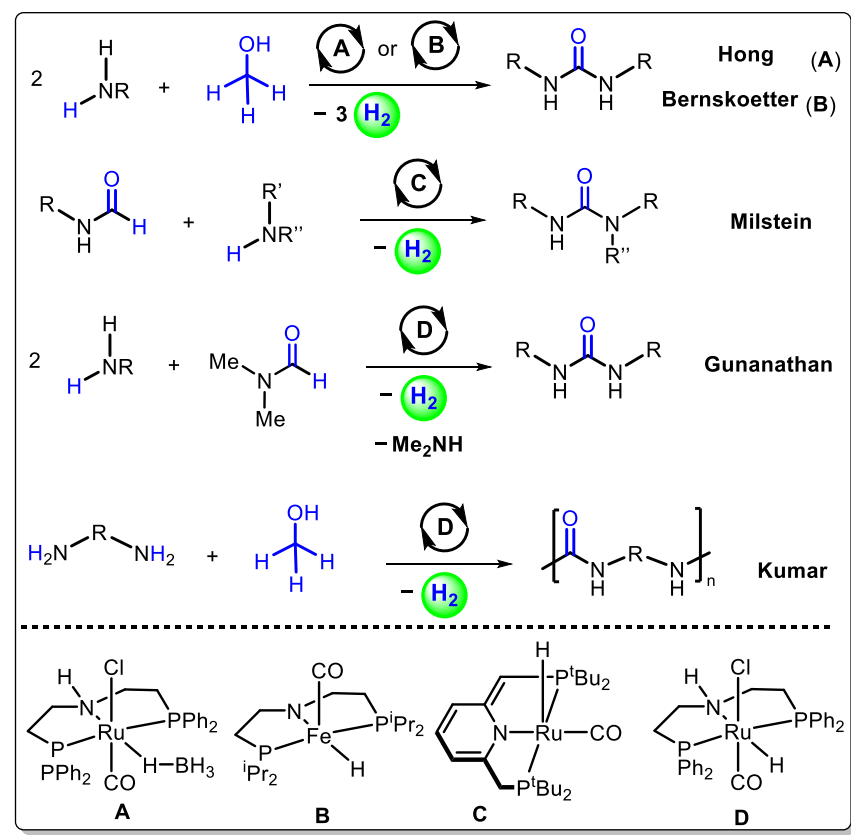

Figure 1. Previous reports on the dehydrogenative synthesis of (poly)ureas.

a catalyst based on precious metal such as ruthenium is less desirable as it is expensive, less abundant, and sometimes toxic which could be a concern if the target compound is a pharmaceutical drug. Several catalysts based on earth-abundant metals have been reported for the (de)hydrogenative transformation in the recent past. ${ }^{27-29}$ Bernskoetter has recently reported the dehydrogenative coupling of amines with methanol for the synthesis of symmetrical urea derivatives using an iron-Macho pincer catalyst (B, Figure 1). ${ }^{30}$ Unsymmetrical ureas were synthesized by the reaction of formamides with amines, albeit with a 
poor substrate scope. These are the only two catalysts reported in the past for the synthesis of a broad scope of urea derivatives from the dehydrogenative coupling of amines and methanol. Prakash, ${ }^{31}$ and Milstein ${ }^{32}$ have also independently studied the dehydrogenative coupling of methanol with diamines to form cyclic ureas for the purpose of developing new hydrogen storage materials using ruthenium pincer catalysts. Along a similar direction, Milstein has recently reported the synthesis of urea derivatives from the dehydrogenative coupling of formamides with amines in the presence of a ruthenium PNP catalyst $(\mathbf{C}$, Figure 1) where the formamide was shown to act as an isocyanante surrogate. ${ }^{33}$ Gunanathan has reported the synthesis of urea derivatives by the dehydrogenative coupling of N,N-dimethylformamide (DMF) and amines in the presence of a ruthenium-Macho complex (D). ${ }^{34}$ The reaction occurs via the formyl $\mathrm{C}-\mathrm{H}$ activation of DMF leading to the elimination of $\mathrm{NMe}_{2} \mathrm{H}$ and the formation of $\mathrm{CO}$ that subsequently reacts with an amine in the presence of the complex $\mathbf{D}$ to form a urea derivative. The concept of the dehydrogenative synthesis of ureas has been recently expanded by us for the synthesis of polyureas from the dehydrogenative coupling of diamines and methanol using the ruthenium-Macho complex D with a TON of up to 100 (Figure 1). ${ }^{35}$

Table 1. Optimization of catalytic conditions for the dehydrogenative coupling of octylamine and methanol. ${ }^{\mathrm{a}}$

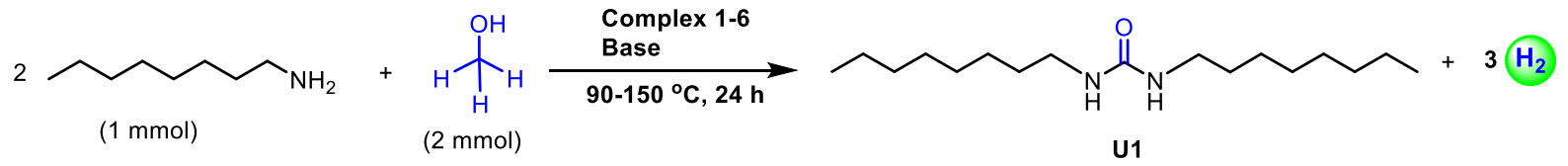

\begin{tabular}{|c|c|c|c|c|c|}
\hline Entry & Complex & Base & Solvent & Temperature & Isolated yield \\
\hline 1. & $1(1 \mathrm{~mol} \%)$ & $\mathrm{KO}^{t} \mathrm{Bu}\left(4 \mathrm{~mol}^{\circ} \%\right)$ & toluene & $120^{\circ} \mathrm{C}$ & $44 \%$ \\
\hline 2. & $2(1 \mathrm{~mol} \%)$ & $\mathrm{KO}^{t} \mathrm{Bu}\left(4 \mathrm{~mol}^{\%}\right)$ & toluene & $120^{\circ} \mathrm{C}$ & $38 \%$ \\
\hline 3. & $3(1 \mathrm{~mol} \%)$ & $\mathrm{KO}^{t} \mathrm{Bu}(4 \mathrm{~mol} \%)$ & toluene & $120^{\circ} \mathrm{C}$ & $25 \%$ \\
\hline 4. & $4(1 \mathrm{~mol} \%)$ & $\mathrm{KO}^{\mathrm{t}} \mathrm{Bu}(4 \mathrm{~mol} \%)$ & toluene & $120^{\circ} \mathrm{C}$ & $0 \%$ \\
\hline 5. & $5(1 \mathrm{~mol} \%)$ & $\mathrm{KO}^{\mathrm{t}} \mathrm{Bu}(4 \mathrm{~mol} \%)$ & toluene & $120^{\circ} \mathrm{C}$ & $0 \%$ \\
\hline 6. & $\mathbf{6}(1 \mathrm{~mol} \%)$ & $\mathrm{KO}^{\mathrm{t}} \mathrm{Bu}(4 \mathrm{~mol} \%)$ & toluene & $120^{\circ} \mathrm{C}$ & $0 \%$ \\
\hline 7. & $5(1 \mathrm{~mol} \%)$ & $\mathrm{KO}^{t} \mathrm{Bu}(4 \mathrm{~mol} \%)$ & toluene & $90^{\circ} \mathrm{C}$ & $0 \%$ \\
\hline 8. & $6(1 \mathrm{~mol} \%)$ & $\mathrm{KO}^{\mathrm{t}} \mathrm{Bu}\left(4 \mathrm{~mol}^{\circ} \mathrm{o}\right)$ & toluene & $90^{\circ} \mathrm{C}$ & $0 \%$ \\
\hline 9. & $1(1 \mathrm{~mol} \%)$ & $\mathrm{KO}^{t} \mathrm{Bu}(4 \mathrm{~mol} \%)$ & anisole & $120^{\circ} \mathrm{C}$ & $45 \%$ \\
\hline 10. & $\mathbf{1}(1 \mathrm{~mol} \%)$ & $\mathrm{KO}^{t} \mathrm{Bu}(4 \mathrm{~mol} \%)$ & THF & $120^{\circ} \mathrm{C}$ & $78 \%$ \\
\hline 11. & $\mathbf{1}(1 \mathrm{~mol} \%)$ & $\mathrm{KO}^{\mathrm{t}} \mathrm{Bu}(4 \mathrm{~mol} \%)$ & THF & $150^{\circ} \mathrm{C}$ & $98 \%$ \\
\hline 12. & $\mathbf{1}(1 \mathrm{~mol} \%)$ & $\mathrm{KOH} \mathrm{(4} \mathrm{mol \% )}$ & THF & $150^{\circ} \mathrm{C}$ & $88 \%$ \\
\hline 13. & $1(1 \mathrm{~mol} \%)$ & $\mathrm{K}_{2} \mathrm{CO}_{3}\left(4 \mathrm{~mol}^{\circ}\right)$ & THF & $150^{\circ} \mathrm{C}$ & $92 \%$ \\
\hline 14. & $\mathbf{1}(1 \mathrm{~mol} \%)$ & - & THF & $150^{\circ} \mathrm{C}$ & $0 \%$ \\
\hline 15. & $1(0.5 \mathrm{~mol} \%)$ & $\mathrm{KO}^{t} \mathrm{Bu}(2 \mathrm{~mol} \%)$ & THF & $150^{\circ} \mathrm{C}$ & $97 \%$ \\
\hline 16. & $1(0.05 \mathrm{~mol} \%)$ & $\mathrm{KO}^{t} \mathrm{Bu}(0.2 \mathrm{~mol} \%)$ & THF & $150^{\circ} \mathrm{C}$ & $68 \%$ \\
\hline $17 .^{\mathrm{b}}$ & $1(0.5 \mathrm{~mol} \%)$ & $\mathrm{KO}^{\mathrm{t}} \mathrm{Bu}(2 \mathrm{~mol} \%)$ & THF & $150{ }^{\circ} \mathrm{C}$ & $45 \%$ \\
\hline 18. & $1(0.5 \mathrm{~mol} \%)$ & $\mathrm{KO}^{\mathrm{t}} \mathrm{Bu}\left(4 \mathrm{~mol}^{\%} \mathrm{o}\right)$ & neat & $150^{\circ} \mathrm{C}$ & $35 \%$ \\
\hline 19. & - & $\mathrm{KO}^{\mathrm{t}} \mathrm{Bu}(4 \mathrm{~mol} \%)$ & THF & $150{ }^{\circ} \mathrm{C}$ & $0 \%$ \\
\hline 20. & $\mathbf{1}(0.5 \mathrm{~mol} \%)$ & $\mathrm{KO}^{t} \mathrm{Bu}(0.5 \mathrm{~mol} \%)$ & THF & $150^{\circ} \mathrm{C}$ & $41 \%$ \\
\hline
\end{tabular}

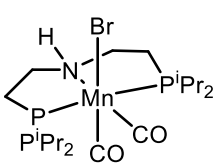

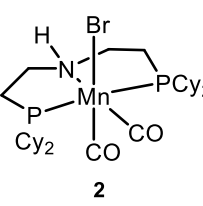

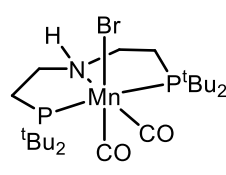

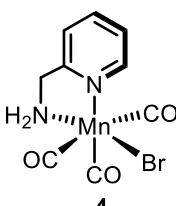

4

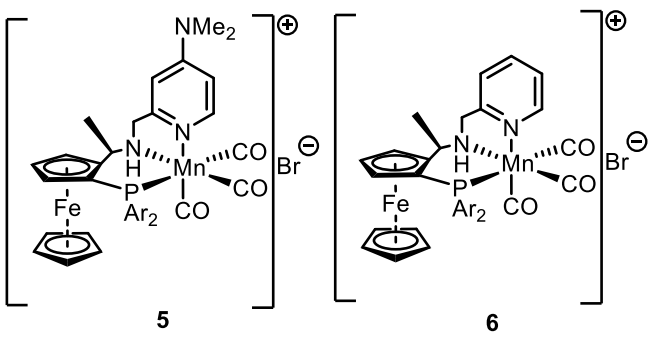

${ }^{a}$ Catalytic conditions: octylamine $(129 \mathrm{mg}, 1 \mathrm{mmol})$, methanol $(0.16 \mathrm{~mL}, 2 \mathrm{mmol})$, solvent $(1 \mathrm{~mL}), 24 \mathrm{~h} . \mathrm{Ar}=3,5-\mathrm{Me}_{2}-4-\mathrm{OMeC}_{6} \mathrm{H}_{2}$.

${ }^{\mathrm{b}} 0.5 \mathrm{mmol}$ of methanol was used. 
Replacement of the ruthenium-based catalyst with a catalyst of earth-abundant-metal can make the overall process more costeffective, and sustainable. We present here the synthesis of a wide variety of urea derivatives and polyureas using a pincer complex of manganese, which is the second most abundant transition metal in the earth's crust. This is the first example of a base-metal catalyst for the dehydrogenative synthesis of polyureas, and the second example for the dehydrogenative synthesis of urea derivatives after the recent report by Bernskoetter (Complex B, Figure 1). Moreover, the use of methanol for the production of useful chemicals and materials makes the process beneficial to the circular economy as $100 \%$ renewable methanol can be directly produced from the hydrogenation of $\mathrm{CO}_{2}$ or from biomass.

We started our investigation by developing optimized catalytic conditions for the dehydrogenative coupling of octyl amine with methanol in the presence of manganese complexes 1-6 most of which have been reported for their excellent activity for (de)hydrogenative transformations. Refluxing a toluene solution $\left(120^{\circ} \mathrm{C}, 24 \mathrm{~h}\right)$ of octyl amine $(1 \mathrm{mmol})$, and methanol $(4$ $\mathrm{mmol}$ ) in the presence of the manganese-Macho pincer complex $1(1 \mathrm{~mol} \%)$, and $\mathrm{KO}^{t} \mathrm{Bu}(4 \mathrm{~mol} \%)$ under the open flow of nitrogen did not result in any conversion of octyl amine presumably due to the low boiling point of methanol $\left(64.7^{\circ} \mathrm{C}\right.$ at $\left.1 \mathrm{bar}\right) . \mathrm{In}-$ terestingly, performing the same reaction in a sealed Young's flask resulted in the $50 \%$ conversion of octyl amine. 1,3-dioctylurea was isolated in $44 \%$ yield (Table 1, entry 1 ). The $\mathrm{PCy}_{2}$ analogue complex 2 resulted in a slightly lower yield of the 1,3dioctylurea whereas no formation of the urea derivative was obtained in the case of complexes 3-6 under analogous conditions as described in Table 1, entries 3-8. As complex 1 was found to be the most active precatalyst for this transformation, we used this complex for further optimization of reaction conditions. Using anisole as a solvent instead of toluene, keeping the remaining conditions same, resulted in a similar yield (45\%, entry 9), whereas a significantly higher yield was obtained in the case of THF ( $78 \%$, entry 10$)$. Remarkably, when the temperature was increased to $150{ }^{\circ} \mathrm{C}$ while using THF as a solvent, a quantitative conversion of octylamine was obtained and 1,3-dioctylurea was isolated in $98 \%$ yield by simple filtration and washing (with hexane) method (entry 11). The use of other bases such as $\mathrm{KOH}$, and $\mathrm{K}_{2} \mathrm{CO}_{3}$ also showed excellent yields (entries 12,13) whereas no conversion of octyl amine was obtained when the reaction was performed in the absence of a base (entry 14). Remarkably, reducing the catalytic loading to $0.5 \mathrm{~mol} \% \mathbf{1}$; $2 \mathrm{~mol} \% \mathrm{KO}^{t} \mathrm{Bu}$ also resulted in an almost quantitative yield of 1,3-dioctylurea exhibiting a TON of 200 (entry 15). Further reduction of the catalytic loading to $0.05 \mathrm{~mol} \% \mathrm{1}$, and $0.2 \mathrm{~mol} \%$ $\mathrm{KO}^{t} \mathrm{Bu}$ resulted in $68 \%$ yield of 1,3-dioctylurea (entry 16). Interestingly, lowering the methanol amount to the reaction stoichiometric value i.e. $0.5 \mathrm{mmol}$, resulted in a lower yield of 1,3dioctylurea (entry 17) presumably due to the low boiling point $\left(64.7^{\circ} \mathrm{C}\right.$ at 1 bar) of methanol keeping its significant part in the gas phase. A low yield (35\%) was obtained when the reaction was performed under the neat condition without using any solvent (entry 18). Finally, performing a control experiment in the absence of a manganese catalyst but in the presence of $2 \mathrm{~mol} \%$ $\mathrm{KO}^{t} \mathrm{Bu}$ did not result in any conversion of octylamine suggestive of the crucial role of the manganese catalyst (entry 19). Interestingly, using $0.5 \mathrm{~mol} \%$ of $\mathrm{KO}^{\mathrm{t}} \mathrm{Bu}$ in combination of 0.5 $\mathrm{mol} \%$ of complex 1 resulted in a lower yield of the product (41\%) suggesting that an additional amount of base albeit in the catalytic amount is needed for a higher yield. Role of bases such as $\mathrm{KO}^{\mathrm{t}} \mathrm{Bu}$ in lowering the barrier of (de)hydrogenation reactions has been suggested before. ${ }^{35}$

Upon optimization of catalytic conditions, we turned our attention to utilize this protocol to synthesize a broad variety of urea derivatives. Gratifyingly, using $0.5 \mathrm{~mol} \%$ of complex 1, and $2 \mathrm{~mol} \% \mathrm{KO}{ }^{t} \mathrm{Bu}\left(\mathrm{THF}, 150{ }^{\circ} \mathrm{C}, 24 \mathrm{~h}\right.$ ) a variety of symmetrical ureas were synthesized in moderate to excellent yields (Figure 2). As mentioned above, almost quantitative yield was obtained in the case of octyl amine (U1). However, a slightly lower yield was obtained in the case of isobutyl amine possibly due to the low boiling point of the amine (U2). Ethoxypropylamine also resulted in the corresponding urea in $80 \%$ yield (U3). Cyclohexyl amine afforded dicyclohexylurea in $85 \%$ yield whereas a relatively lower yield was obtained in the case of cyclopentyl amine. (U4, U5). Excellent yields were obtained in the case of benzylamine and its derivatives (U6-U9). Panisidine resulted in poor yield of corresponding urea derivatives even at longer reaction time $(72 \mathrm{~h})$ presumably due to poor nucleophilicity of amines. Moreover, secondary amines such as $\mathrm{N}$-methyl benzylamine, and N,N-dicyclohexylamine also resulted in poor yields even at longer reaction time $(72 \mathrm{~h})$ possibly due to higher steric hindrance.

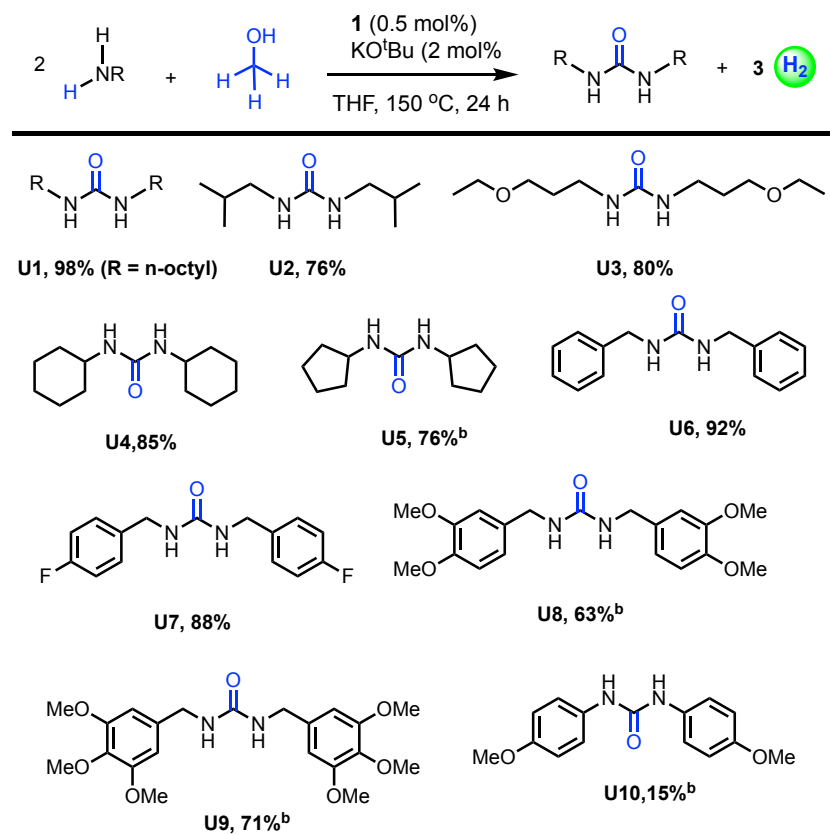

Figure 2. Dehydrogenative synthesis of symmetrical urea derivatives using the manganese complex 1. $1(0.005 \mathrm{mmol}), \mathrm{KO}^{\mathrm{t}} \mathrm{Bu}$ $(0.02 \mathrm{mmol})$, amine $(1 \mathrm{mmol})$, and methanol $(0.16 \mathrm{~mL}, 2 \mathrm{mmol})$. ${ }^{b}$ Yield estimated by ${ }^{1} \mathrm{H}$ NMR spectroscopy and GC-MS

Although dehydrogenative synthesis of symmetrical urea derivatives using a manganese catalyst is interesting, several examples of urea containing agrochemicals or pharmaceutical drugs involve unsymmetrical urea derivatives. ${ }^{3-6}$ We utilized the approach of coupling formamide with amines to form unsymmetrical urea derivatives. This approach has been previously demonstrated by Milstein ${ }^{33}$ and Bernskoetter ${ }^{30}$ using a ruthenium and an iron pincer catalyst, respectively. Gratifyingly, using manganese pincer complex $1(0.5 \mathrm{~mol} \%)$, and $\mathrm{KO}^{\mathrm{t}} \mathrm{Bu}(2$ mol\%), several unsymmetrical urea derivatives were synthesized from the dehydrogenative coupling of N-benzylformamide and amines in very good to excellent yields as described in Figure 3. 


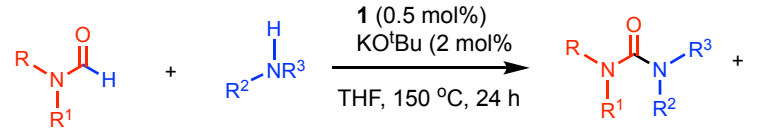

$$
\underbrace{}_{U 11,85 \% \%^{b}(R=\text { i-butyl) }}
$$<smiles>COc1ccc(CNC(=O)NCc2ccccc2)cc1OC</smiles><smiles>COc1cc(CNC(=O)NC2CCCCC2)cc(OC)c1</smiles><smiles>O=C(NCc1ccc(C(F)(F)F)cc1)NC1CCCCC1</smiles><smiles>[R]NC(=O)Nc1ccc(Cl)cc1</smiles><smiles>[R]NC(=O)NC1CCCCC1</smiles>

U16, $66 \%^{\mathrm{b}}$

$\mathrm{U} 17,78 \%{ }^{\mathrm{b}}(\mathrm{R}=$ octyl $)$

U18, $56 \%$ b
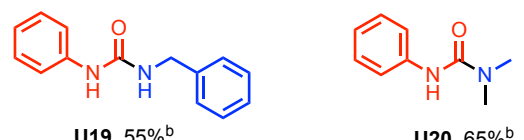

U20, $65 \%^{\mathrm{b}}$

Figure 3. Dehydrogenative synthesis of unsymmetrical urea derivatives using the manganese complex $\mathbf{1}$. $1(0.005 \mathrm{mmol}), \mathrm{KO}^{\mathrm{t}} \mathrm{Bu}$ $(0.02 \mathrm{mmol})$, formamide $(1 \mathrm{mmol})$, amine $(1.5 \mathrm{mmol})$. ' ${ }^{\text {Yield es- }}$ timated by ${ }^{1} \mathrm{H}$ NMR spectroscopy and GC-MS.

Having accomplished the synthesis of a wide variety of urea derivatives, we expanded this catalytic protocol to demonstrate the dehydrogenative synthesis of polyureas which have not been achieved before using a catalyst of an earth-abundant metal. Gratifyingly, using $1 \mathrm{~mol} \%$ of complex 1 and $4 \mathrm{~mol} \%$ of $\mathrm{KO}^{\mathrm{t}} \mathrm{Bu}$, we synthesized various polyureas in good to excellent yields (Table 2). Polyureas were characterized by NMR and IR spectroscopy as well as MALDI-TOF mass spectrometry. Due to the insolubility of polyureas in common organic solvents such as THF, toluene, and DMF, we were unable to estimate the molecular weight and PDI of polymers using GPC, and therefore the number average molecular weight $\left(\mathrm{M}_{\mathrm{n}}\right)$ of the isolated polymers were estimated using the ${ }^{1} \mathrm{H}$ NMR spectroscopy. The thermal stability of the polyureas was studied using the thermogravimetric analysis (TGA) that showed that the polyureas are stable up to $230-348{ }^{\circ} \mathrm{C}$. Decomposition temperatures $\left(\mathrm{T}_{\mathrm{d}}\right)$ were calculated by $10 \%$ weight loss in the TGA experiments. Melting temperature $\left(\mathrm{T}_{\mathrm{m}}\right)$ and the glass transition temperature $\left(\mathrm{T}_{\mathrm{g}}\right)$ were estimated by the DSC analysis and found to vary with the change of diamine.

Furthermore, we also demonstrated the synthesis of a polyurea from the dehydrogenative coupling of diformamide and diamine using the catalytic conditions described in Table 2 (Scheme 1). The corresponding polyurea was isolated in $70 \%$ yield and exhibited a decomposition temperature of $285^{\circ} \mathrm{C}$ as estimated by the TGA study.

Having demonstrated the application of manganese pincer catalyst $\mathbf{1}$ for the dehydrogenative synthesis of a broad scope of urea derivatives and polyureas, we carried studies to gain insights into the mechanism of the dehydrogenative coupling reaction. When the catalytic reaction between octyl amine and methanol as per the conditions of Table 1, entry 15 was stopped after $6 \mathrm{~h}$, formation of N-octylformamide and 1,3-dioctylurea (U1) was obtained in $10 \%$ and $30 \%$ yields, respectively. This suggests that the formation of urea derivatives occurs via a formamide intermediate presumably formed from the reaction of amine and methanol. This is in agreement with the ability of complex 1 to dehydrogenative couple formamides and amines to form urea derivatives as demonstrated in Figure 3.

Table 2. Substrate scope for the dehydrogenative synthesis of polyureas.

$$
\begin{aligned}
& \text { 2. } \\
& \text { 2. }
\end{aligned}
$$

Scheme 1. Synthesis of polyurea from the dehydrogenative coupling of diformamide and diamine.

Based on the previous studies, ${ }^{26,30,33}$ and our mechanistic investigations, we suggest that the dehydrogenative synthesis of urea derivatives occurs via three steps where each step releases one equivalent of $\mathrm{H}_{2}$ : (a) dehydrogenation of methanol to form formaldehyde, (b) dehydrogenative coupling of formaldehyde and amine to form a formamide, and (c) dehydrogenative coupling of formamide with another equivalent of amine to form the urea molecule. We carried DFT calculations at the PBE0-D3/def2TZVP/PCM//RI-BP86/def2-SVP/PCM level to get deeper insights into pathways for the occurrence of these steps as described below.

Step1: Dehydrogenation of methanol to formaldehyde: The manganese pincer complex 1 has been previously utilized for the dehydrogenative coupling of alcohols. ${ }^{36-43}$ Based on the previous studies, we suggest that complex 1 reacts with a base such as $\mathrm{KO}^{t} \mathrm{Bu}$ to form the manganese-amido complex 7 that acts as an active species in catalysis. A pathway to the dehydrogenation of methanol to formaldehyde by complex $\mathbf{7}$ is outlined in Figure 4A. The amido site of the complex 7 abstracts a proton from 
methanol through transition state TSI that appears to be shallow on the potential energy surface.

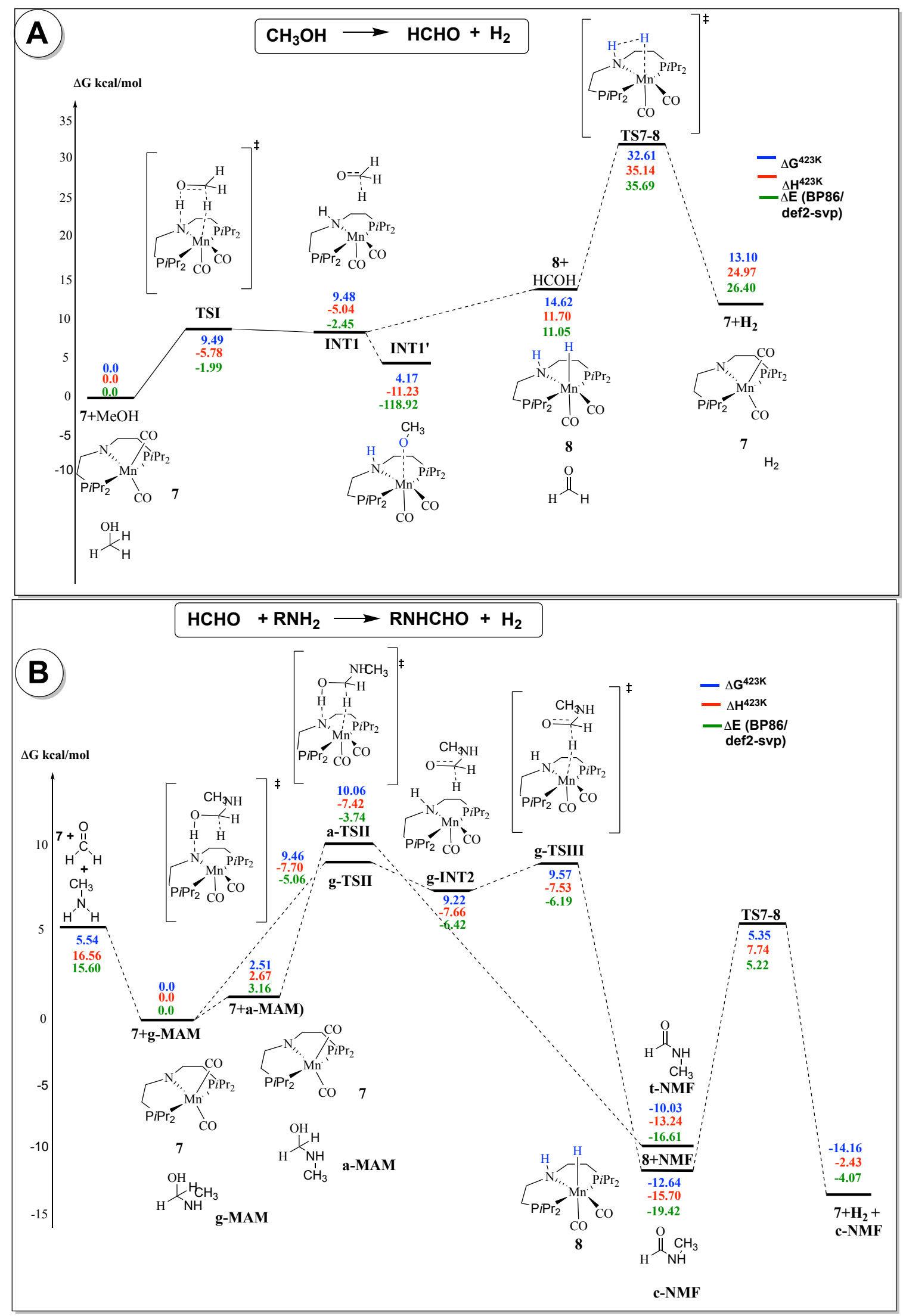

Figure 4. Free energy profile for (A) dehydrogenation of methanol using catalyst 7 to give formaldehyde, and (B) synthesis of formamides from the dehydrogenative coupling of amines and methanol (using methylamine as a model substrate, PBE0-D3/def2TZVP/PCM//RI-BP86/def2-SVP/PCM level). 
A similar step has been reported for the DFT computation by Jiao and Beller for the dehydrogenation of methanol to formaldehyde. ${ }^{44}$ TSI leads to the formation of a zwitterionic intermediate (INT1), with a driving force of $\Delta \mathrm{G}=9.48 \mathrm{kcal} / \mathrm{mol}$. Formally INT1 can be described as a complex between a N-protonated complex $\left(7-\mathrm{H}^{+}\right)$with methoxide ion $\left(\mathrm{MeO}^{-}\right)$, with a strong (agostic) interaction between a $\mathrm{CH}$ bond of the latter and the metal (BP86 optimized $\mathrm{C} \cdots \mathrm{H}$ and $\mathrm{Mn} \cdots \mathrm{H}$ distances of 1.18 and $1.86 \AA$, respectively). Starting from INT1, formaldehyde dissociates to form the Mn-dihydride complex 8, with no apparent barrier on the potential energy surface (in a scan at the BP86 level, the energy rises continuously as the C...H distance is increased). The free energy for the full dissociation of formaldehyde is $\Delta \mathrm{G}=14.6 \mathrm{kcal} / \mathrm{mol}$ relative to the reactants $(7+$ $\mathrm{MeOH})$. The regeneration of the active catalyst can be achieved by the dehydrogenation of complex 8 proceeding through TS78. This is the rate-determining barrier with a free activation energy of $\Delta \mathrm{G}^{*}=32.6 \mathrm{kcal} / \mathrm{mol}$ relative to 7 . The overall process of the methanol dehydrogenation is computed to be endergonic by $\Delta \mathrm{G}=13.1 \mathrm{kcal} / \mathrm{mol}$. It is noteworthy that the agostic intermediate INT1 can rearrange to a zwitterionic methoxide complex INT1', which is slightly lower in energy (by $\Delta \mathrm{G}=-5.3$ $\mathrm{kcal} / \mathrm{mol}$ ) than INT1, but this does not affect the kinetics or thermodynamics of the overall catalytic cycle.

Step 2: Synthesis of formamide from the dehydrogenative coupling of formaldehyde and amine: The formed formaldehyde reacts with an amine to form a hemiaminal that releases $\mathrm{H}_{2}$ to form a formamide. Sola and Poater have recently reported a DFT study on the synthesis of formamides from the dehydrogenative coupling of methanol and amines catalysed by a manganese pincer complex originally reported by Milstein. ${ }^{45,46}$ The proposed mechanism suggests that formaldehyde and amine react off-metal to form a hemiaminal intermediate that subsequently gets dehydrogenated in the presence of the manganese pincer complex to form the formamide. Using methylamine as model substrate, our DFT calculations aligns with this sequence. The proposed pathway for the dehydrogenative coupling of formaldehyde with the model methylamine to form Nmethylformamide (NMF) and $\mathrm{H}_{2}$ starts with the off-metal formation of a hemiaminal, N-methylaminomethanol (MAM). This intermediate can exist in two conformations, gauche and anti with respect to the O-C-N-C dihedral angle. At our DFT level, the gauche conformer, g-MAM, is more stable than the anti-form (a-MAM) by $2.5 \mathrm{kcal} / \mathrm{mol}$ and its formation from the reactants is computed to be exergonic by $\Delta \mathrm{G}=-5.5 \mathrm{kcal} / \mathrm{mol}$. Likewise, the final product NMF can exist in two isomeric forms, cis and trans relative to the $(\mathrm{O}) \mathrm{C}-\mathrm{N}(\mathrm{C})$ bond, of which cis (c-NMF) is more stable than trans by $2.6 \mathrm{kcal} / \mathrm{mol}$. Dehydrogenation of the MAM conformer by the active catalyst 7 may be expected to proceed in analogy to that of $\mathrm{MeOH}$ (vide supra), with two possible pathways, one linking g-MAM with c-NMF, and the other linking the other isomers, i.e. anti-Nmethylaminomethanol (a-MAM) with trans-N-methylformamide (t-NMF). The situation is slightly complicated by the observation that a stable agostic zwitterionic intermediate akin to INT1 is only found on one of these pathways, namely starting from g-MAM (labelled INT2) via g-TSII. The analoguous TS on the anti pathway, a-TSII, does not connect to a zwitterionic intermediate, but is a concerted TS for transfer of both $\mathrm{H}$ atoms (though asynchronous, because protonation of the $\mathrm{N}$ atom of catalyst 7 occurs before hydride transfer to the metal), affording the product t-NMF directly. The rate-limiting step is again indicated to be regeneration of the active catalyst 7 from 8 , but now with an overall barrier $\Delta \mathrm{G}^{\ddagger}$ of only $18.0 \mathrm{kcal} / \mathrm{mol}$. Production of formamide is thus indicated to be very rapid under the reaction conditions.

Step 3: Dehydrogenative coupling of formamide with another equivalent of amine: The third step that is the dehydrogenative coupling of formamide and amine to form urea, can occur via two pathways (Scheme 2): (a) formamide can react with amine to form a bisamino methanol type intermediate followed by its subsequent dehydrogenation to form urea, or (b) formamide can dehydrogenate to form an isocyanate that subsequently reacts with an amine to form a urea. The mechanistic studies conducted by Milstein using the ruthenium pincer complex $\mathbf{C}$ suggested the later pathway. ${ }^{33}$

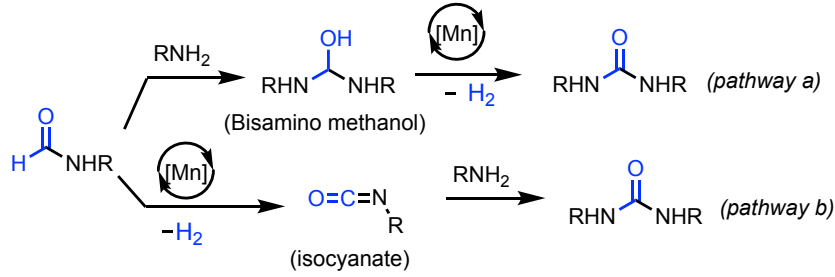

Scheme 2. Possible pathways for the dehydrogenative coupling of formamide with amine to form a urea derivative.

We performed control experiments to verify which pathway is more likely to occur. Our attempt to perform dehydrogenative coupling of a secondary amine with methanol to form a substituted urea was not successful (see SI). Moreover, the reaction of benzylamine with $\mathrm{N}, \mathrm{N}$-dibutylformamide did not result in the formation of a urea derivative (Scheme 3). This is suggestive of the isocyanate pathway as an isocyanate intermediate will not be formed in the case of disubstituted formamide due to the lack of an N-H proton. Interestingly, a reaction of benzylformamide and $\mathrm{N}, \mathrm{N}$-dibutylamine resulted in the formation of the corresponding urea product in $70 \%$ yield (Scheme 3 ). It is noteworthy that both the above-mentioned reactions will form the same aminal intermediate as per the pathway $a$ of the Scheme 2. This experiment, thus, is supportive of the pathway $b$. Furthermore, we performed the reactions of N-methylformanilide with primary amines such as octyl amine and benzylamine (Scheme 4). Although N-methylformanilide is a disubstituted formamide without $\mathrm{N}-\mathrm{H}$ proton, it is less bulky compared to N,N-dibutylformamide. Interestingly, in these cases symmetrical urea derivatives (dioctylurea, dibenzylurea) were formed with $\mathrm{N}$-methylaniline as the by-product (observed by the GCMS). We suggest these proceed via reaction of N-methylformanilide with an amine to form an aminal intermediate which instead of dehydrogenating eliminates $\mathrm{N}$-methylaniline to form an $\mathrm{N}$-alkyl formamide containing an $\mathrm{N}-\mathrm{H}$ proton. The formamide reacts with the remaining amine to form the corresponding symmetrical urea derivative (Scheme 4). These experiments further support the hypothesis that the presence of an N-H proton on the formamide is crucial to the formation of urea derivatives. 


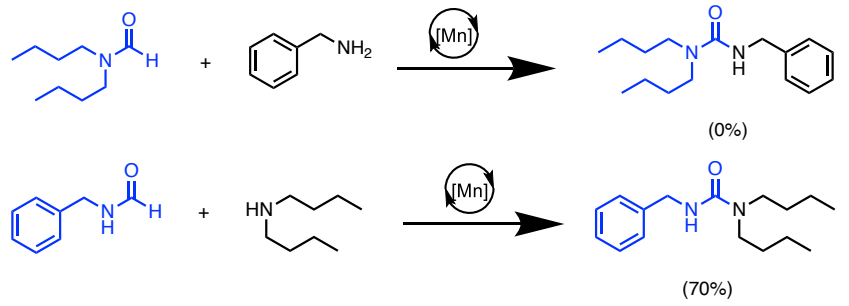

Scheme 3. Control experiments in support of pathway $b$.

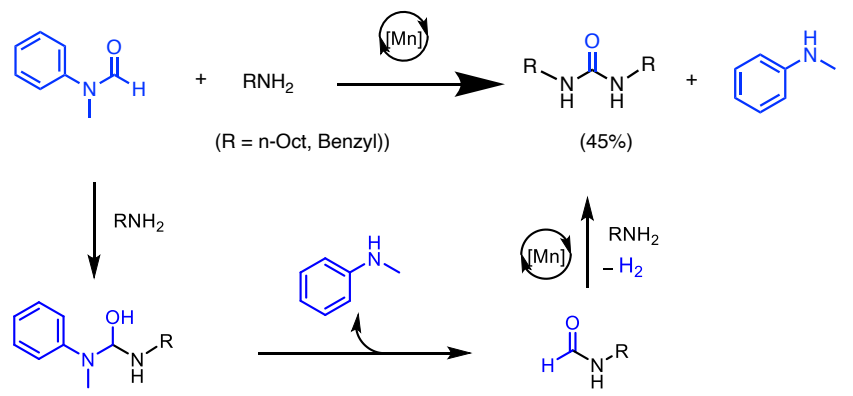

Scheme 4. Reaction of N-methylformanilide with octyl amine, and benzylamine.

Our DFT results fully agree with this interpretation. Dehydrogenation of formamide is predicted to proceed via a zwitterionic intermediate akin to that involved in methanol dehydrogenation (labelled TSI in Figure 4A), namely INT3 in Figure 5, and a transition state (TSV) with a moderately high barrier of $\Delta \mathrm{G}^{\ddagger}=$ $23.3 \mathrm{kcal} / \mathrm{mol}$ (Figure 5).

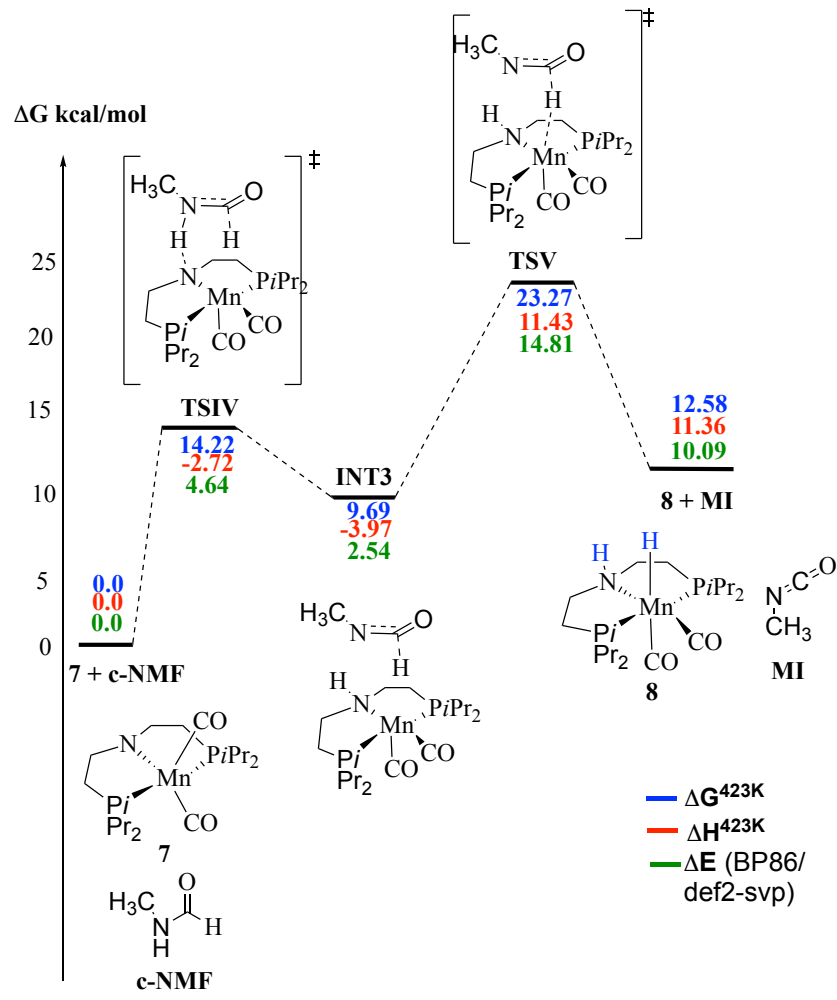

Figure 5. Key steps for isocyanate formation with the active catalyst 7 from DFT (using cis-N-methylformamide, c-NMF, and methyl isocyanide, MI, as model substrates, PBE0-D3/def2TZVP/PCM//RI-BP86/def2-SVP/PCM level).
As in the Mn-catalyzed dehydrogenation steps discussed above, regeneration of the active catalyst 7 from $\mathbf{8}$ is indicated to be rate-limiting with an overall barrier of $\Delta \mathrm{G}^{*}=30.6 \mathrm{kcal} / \mathrm{mol}$ (see full profile in Scheme S2). This barrier is similar to (and even slightly lower than) that for methanol dehydrogenation (32.6 $\mathrm{kcal} / \mathrm{mol}$, vide supra, Figure $4 \mathrm{~A}$ ), confirming the isocyanate pathway as a viable route. The isocyanate product would be removed from this mixture through rapid reaction with an amine, affording the urea product (computed driving force for the model reaction $\mathrm{MeNCO}+\mathrm{MeNH}_{2} \rightarrow \mathrm{N}, \mathrm{N}^{\prime}$-dimethylurea is $\Delta \mathrm{G}$ $=-3.5 \mathrm{kcal} / \mathrm{mol}$ at our DFT level).

In contrast, much higher barriers are computed for the aminal route (pathway a of Scheme 2). While catalytic dehydrogenation of a model aminal is indicated to be kinetically feasible at our DFT level, the formation of such an aminal from the formamide and alkylamine is so unfavourable (computed $\Delta \mathrm{G}=20.6$ $\mathrm{kcal} / \mathrm{mol}$ for the methylated models) that the overall barrier is raised to $\Delta \mathrm{G}^{*}=38.3 \mathrm{kcal} / \mathrm{mol}$ (see Schemes $\mathrm{S} 4$ and S5). This value is significantly higher than that computed for the isocyanate route $\left(\Delta \mathrm{G}^{\ddagger}=30.6 \mathrm{kcal} / \mathrm{mol}\right.$, see above $)$, suggesting that it is the latter pathway that is followed essentially exclusively, in full accord with the experiment.

\section{CONCLUSIONS:}

In conclusion, we report here the dehydrogenative synthesis of urea derivatives and polyureas using a manganese pincer catalyst. Urea derivatives and polyureas are synthesized by the dehydrogenative coupling of (di)amines and methanol or using (di)formamides and amines. Only one example of the earthabundant metal catalyst (iron-macho catalyst) has been reported before for the synthesis of urea derivatives although selectivity and substrate scope for the unsymmetrical urea derivatives were poor. This is the first example of an earth-abundant metal catalyst for the synthesis of polyureas. We also report here our mechanistic studies supported by both experiments and DFT computation and suggest that the formation of urea derivatives proceeds via an isocyanate intermediate. Overall, this methodology presents a sustainable alternative to the current state of the art for the production of ureas and polyureas by virtue of being atom-economic, using an earth-abundant metal catalyst, and avoiding toxic reagents such as phosgene and isocyanates.

\section{ASSOCIATED CONTENT}

\section{Supporting Information}

Supporting information is available at the ChemRxiv website and contains experimental details of catalytic dehydrogenation, synthesis/characterization of (poly)ureas, mechanistic studies, NMR, IR, MALDI-TOF mass spectrometry and computational details.

\section{AUTHOR INFORMATION}

\section{Corresponding Author}

* Amit Kumar (ak336@st-andrews.ac.uk)

* Michael Bühl (mb105@st-andrews.ac.uk)

$\dagger \mathrm{AP}, \mathrm{AM}$, and $\mathrm{CG}$ contributed equally.

\section{Notes}

The authors declare no competing financial interest. 


\section{ACKNOWLEDGMENT}

AK thanks the Leverhulme Trust for an early career fellowship (ECF-2019-161). We thank Prof. Matt Clarke and his research group (School of Chemistry, University of St. Andrews) for assisting with lab equipment/facilities and donating complexes 4 (by Nina Jeffrey), and 5-6 (by Conor Oates). M.B. wishes to thank the School of Chemistry and EaStCHEM for support. A. E. O. gratefully acknowledges a fellowship from the Akwa Ibom State University (TETFund). Calculations were performed on a local compute cluster maintained by Dr H. Früchtl. A.P. thanks the Royal Society of Chemistry for an undergraduate research bursary award.

\section{REFERENCES}

(1) Urea-Formaldehyde Resins. Adhesives for Wood and Lignocellulosic Materials. July 19, 2019, pp 61-100. https://doi.org/https://doi.org/10.1002/9781119605584.ch3. Patel, M. J.; Tandel, R. C. Synthesis of Reactive Dyes by the Introduction of Phenyl Urea Derivatives into the Triazine Ring and Their Application on Different Fibers. Mater. Today Proc. 2021, 46 , $6459-6464$ https://doi.org/https://doi.org/10.1016/j.matpr.2021.03.575 elnikov, N. N. Derivatives of Urea and Thiourea BT Chemistry of Pesticides; Melnikov, N. N., Gunther, F. A., Gunther, J. D., Eds.; Springer US: New York, NY, 1971; pp 225239. https://doi.org/10.1007/978-1-4684-6251-7 18.

(4) Morais, S. Urea Pesticides; Correia, M., Ed.; IntechOpen: Rijeka, 2011; p Ch. 10. https://doi.org/10.5772/13126.

(5) Ronchetti, R.; Moroni, G.; Carotti, A.; Gioiello, A.; Camaioni, E. Recent Advances in Urea- and Thiourea-Containing Compounds: Focus on Innovative Approaches in Medicinal Chemistry and Organic Synthesis. RSC Med. Chem. 2021, 12 (7), 1046-1064. https://doi.org/10.1039/D1MD00058F

6) Ghosh, A. K.; Brindisi, M. Urea Derivatives in Modern Drug Discovery and Medicinal Chemistry. J. Med. Chem. 2020, 63 (6), 2751-2788. https://doi.org/10.1021/acs.jmedchem.9b01541.

(7) Yokoya, M.; Kimura, S.; Yamanaka, M. Urea Derivatives as Functional Molecules: Supramolecular Capsules, Supramolecular Polymers, Supramolecular Gels, Artificial Hosts, and Catalysts. Chem. - A Eur. J. 2021, 27 (18), 5601-5614. https://doi.org/https://doi.org/10.1002/chem.202004367.

(8) Shojaei, B.; Najafi, M.; Yazdanbakhsh, A.; Abtahi, M.; Zhang, C. A Review on the Applications of Polyurea in the Construction Industry. Polym. Adv. Technol. 2021, 32 (8), 2797-2812. https://doi.org/https://doi.org/10.1002/pat.5277.

(9) Rocas, P.; Cusco, C.; Rocas, J.; Albericio, F. On the Importance of Polyurethane and Polyurea Nanosystems for Future Drug Delivery. Curr. Drug Deliv. 2018, $15 \quad$ (1). https://doi.org/10.2174/1567201814666171019102537.

(10) Bigi, F.; Maggi, R.; Sartori, G. Selected Syntheses of Ureas through Phosgene Substitutes. Green Chemistry. Royal Society of Chemistry 2000, pp 140-148. https://doi.org/10.1039/b002127j.

(11) Mane, M.; Balaskar, R.; Gavade, S.; Pabrekar, P.; Mane, D. An Efficient and Greener Protocol towards Synthesis of Unsymmetrical N,N'-Biphenyl Urea. Arab. J. Chem. 2013, 6 (4), 423-427.

https://doi.org/https://doi.org/10.1016/j.arabjc.2011.01.030

(12) Guan, Z.-H.; Lei, H.; Chen, M.; Ren, Z.-H.; Bai, Y.; Wang, Y.Y. Palladium-Catalyzed Carbonylation of Amines: Switchable Approaches to Carbamates and N,N'-Disubstituted Ureas. $A d v$ Synth. Catal. 2012, $354 \quad(2-3), \quad 489-496$. https://doi.org/https://doi.org/10.1002/adsc.201100545.

(13) Wang, P.; Fei, Y.; Long, Y.; Deng, Y. Catalytic Polymerization of CO2 to Polyureas over K3PO4 Catalyst. J. CO2 Util. 2018, 28 , 403-407. https://doi.org/10.1016/j.jcou.2018.10.020.

(14) Wu, C.; Wang, J.; Chang, P.; Cheng, H.; Yu, Y.; Wu, Z.; Dong, D.; Zhao, F. Polyureas from Diamines and Carbon Dioxide: Synthesis, Structures and Properties. Phys. Chem. Chem. Phys. 2012, 14 (2), 464-468. https://doi.org/10.1039/c1cp23332g.

(15) Jiang, S.; Cheng, H. Y.; Shi, R. H.; Wu, P. X.; Lin, W. W.; Zhang, C.; Arai, M.; Zhao, F. Y. Direct Synthesis of Polyurea Thermoplastics from $\mathrm{CO} 2$ and Diamines. ACS Appl. Mater. Interfaces $\quad \mathbf{2 0 1 9}, \quad 11 \quad$ (50), 47413-47421. https://doi.org/10.1021/acsami.9b17677.

Ying, Z.; Zhao, L.; Zhang, C.; Yu, Y.; Liu, T.; Cheng, H.; Zhao, F. Utilization of Carbon Dioxide to Build a Basic Block for Polymeric Materials: An Isocyanate-Free Route to Synthesize a Soluble Oligourea. RSC Adv. 2015, 5 (52), 42095-42100. https://doi.org/10.1039/c5ra02819a.

Kumar, A.; Gao, C. Homogeneous (De)Hydrogenative Catalysis for Circular Chemistry - Using Waste as a Resource. ChemCatChem 2021, 13 (4), 1105-1134. https://doi.org/10.1002/cctc.202001404.

Shimbayashi, T.; Fujita, K. I. Recent Advances in Homogeneous Catalysis via Metal-Ligand Cooperation Involving Aromatization and Dearomatization. Catalysts 2020, 10 (6), 172. https://doi.org/10.3390/catal10060635.

Hunsicker, D. M.; Dauphinais, B. C.; Mc Ilrath, S. P.; Robertson, N. J. Synthesis of High Molecular Weight Polyesters via In Vacuo Dehydrogenation Polymerization of Diols. Macromol. Rapid Commun. 2012, 33 (3), 232-236. https://doi.org/10.1002/marc.201100653.

Gnanaprakasam, B.; Balaraman, E.; Gunanathan, C.; Milstein, D. Synthesis of Polyamides from Diols and Diamines with Liberation of H2. J. Polym. Sci. Part A Polym. Chem. 2012, 50 (9), 1755-1765. https://doi.org/10.1002/pola.25943.

Zeng, H.; Guan, Z. Direct Synthesis of Polyamides via Catalytic Dehydrogenation of Diols and Diamines. J. Am. Chem. Soc. 2011, 133 (5), 1159-1161. https://doi.org/10.1021/ja106958s.

Gunanathan, C.; Milstein, D. Applications of Acceptorless Dehydrogenation and Related Transformations in Chemical Synthesis. Science 2013, $341 \quad$ (6143). https://doi.org/10.1126/science.1229712.

Crabtree, R. H. Homogeneous Transition Metal Catalysis of Acceptorless Dehydrogenative Alcohol Oxidation: Applications in Hydrogen Storage and to Heterocycle Synthesis. Chemical Reviews. American Chemical Society July 12, 2017, pp 9228 9246. https://doi.org/10.1021/acs.chemrev.6b00556.

Bonitatibus, P. J.; Chakraborty, S.; Doherty, M. D.; Siclovan, O.; Jones, W. D.; Soloveichik, G. L. Reversible Catalytic Dehydrogenation of Alcohols for Energy Storage. Proc. Natl. Acad. Sci. 2015, 112 (6), 1687 LP $\quad 1692$. https://doi.org/10.1073/pnas.1420199112.

Heravi, M. R. P.; Hosseinian, A.; Rahmani, Z.; Ebadi, A.; Vessally, E. Transition-Metal-Catalyzed Dehydrogenative Coupling of Alcohols and Amines: A Novel and AtomEconomical Access to Amides. J. Chinese Chem. Soc. 2021, 68 (5),

https://doi.org/https://doi.org/10.1002/jccs.202000301.

Kim, S. H.; Hong, S. H. Ruthenium-Catalyzed Urea Synthesis Using Methanol as the C1 Source. Org. Lett. 2016, 18 (2), 212 215. https://doi.org/10.1021/acs.orglett.5b03328.

Alig, L.; Fritz, M.; Schneider, S. First-Row Transition Metal (De)Hydrogenation Catalysis Based on Functional Pincer Ligands. Chem. Rev. 2019, 119 (4), 2681-2751. https://doi.org/10.1021/acs.chemrev.8b00555.

Mukherjee, A.; Milstein, D. Homogeneous Catalysis by Cobalt and Manganese Pincer Complexes. ACS Catal. 2018, 8 (12), 11435-11469. https://doi.org/10.1021/acscatal.8b02869.

Piccirilli, L.; Lobo Justo Pinheiro, D.; Nielsen, M. Recent Progress with Pincer Transition Metal Catalysts for Sustainability. $\quad$ Catalysts 2020. https://doi.org/10.3390/catal10070773.

Lane, E. M.; Hazari, N.; Bernskoetter, W. H. Iron-Catalyzed Urea Synthesis: Dehydrogenative Coupling of Methanol and Amines. Chem. Sci. 2018, 9 (16), 4003-4008. https://doi.org/10.1039/c8sc00775f

Kothandaraman, J.; Kar, S.; Sen, R.; Goeppert, A.; Olah, G. A.; Prakash, G. K. S. Efficient Reversible Hydrogen Carrier System Based on Amine Reforming of Methanol. J. Am. Chem. Soc. 2017, 139 (7), 2549-2552. https://doi.org/10.1021/jacs.6b11637. Xie, Y.; Hu, P.; Ben-David, Y.; Milstein, D. A Reversible Liquid Organic Hydrogen Carrier System Based on MethanolEthylenediamine and Ethylene Urea. Angew. Chem. Int. Ed. 2019, 58 (15), 5105-5109. https://doi.org/https://doi.org/10.1002/anie.201901695.

Bruffaerts, J.; Von Wolff, N.; Diskin-Posner, Y.; Ben-David, Y.; Milstein, D. Formamides as Isocyanate Surrogates: A 
Mechanistically Driven Approach to the Development of AtomEfficient, Selective Catalytic Syntheses of Ureas, Carbamates, and Heterocycles. J. Am. Chem. Soc. 2019, 141 (41), 1648616493. https://doi.org/10.1021/jacs.9b08942.

(34) Krishnakumar, V.; Chatterjee, B.; Gunanathan, C. RutheniumCatalyzed Urea Synthesis by N-H Activation of Amines. Inorg. $\begin{array}{lllll}\text { Chem. } & \mathbf{2 0 1 7}, & 56 & \text { (12), } & \text { 7278-7284 }\end{array}$ https://doi.org/10.1021/acs.inorgchem.7b00962.

(35) Kumar, A.; Armstrong, D.; Peters, G.; Nagala, M.; Shirran, S. Direct Synthesis of Polyureas from the Dehydrogenative Coupling of Diamines and Methanol. Chem. Commun. 2021. https://doi.org/10.1039/D1CC01121A.

(36) Elangovan, S.; Neumann, J.; Sortais, J.-B.; Junge, K.; Darcel, C. Beller, M. Efficient and Selective N-Alkylation of Amines with Alcohols Catalysed by Manganese Pincer Complexes. Nat. Commun. 2016, 7 (1), 12641. https://doi.org/10.1038/ncomms12641.

(37) Peña-López, M.; Piehl, P.; Elangovan, S.; Neumann, H.; Beller, M. Manganese-Catalyzed Hydrogen-Autotransfer $\mathrm{C}-\mathrm{C}$ Bond Formation: $\alpha$-Alkylation of Ketones with Primary Alcohols. Angew. Chem. Int. Ed. 2016, 55 (48), 14967-14971. https://doi.org/https://doi.org/10.1002/anie.201607072.

(38) Nguyen, D. H.; Trivelli, X.; Capet, F.; Paul, J.-F.; Dumeignil, F.; Gauvin, R. M. Manganese Pincer Complexes for the Base-Free, Acceptorless Dehydrogenative Coupling of Alcohols to Esters: Development, Scope, and Understanding. ACS Catal. 2017, 7 (3), 2022-2032. https://doi.org/10.1021/acscatal.6b03554.

(39) Kaithal, A.; van Bonn, P.; Hölscher, M.; Leitner, W. Manganese(I)-Catalyzed $\beta$-Methylation of Alcohols Using Methanol as C1 Source. Angew. Chem. Int. Ed. 2020, 59 (1), 215220. https://doi.org/https://doi.org/10.1002/anie.201909035.

(40) Andérez-Fernández, M.; Vogt, L. K.; Fischer, S.; Zhou, W.; Jiao, H.; Garbe, M.; Elangovan, S.; Junge, K.; Junge, H.; Ludwig, R.; Beller, M. A Stable Manganese Pincer Catalyst for the Selective Dehydrogenation of Methanol. Angew. Chem. Int. Ed. 2017, 56 (2), 559-562. https://doi.org/10.1002/anie.201610182.

(41) Liu, Y.; Shao, Z.; Wang, Y.; Xu, L.; Yu, Z.; Liu, Q. ManganeseCatalyzed Selective Upgrading of Ethanol with Methanol into Isobutanol. ChemSusChem 2019, 12 (13), 3069-3072. https://doi.org/https://doi.org/10.1002/cssc.201802689.

(42) Fu, S.; Shao, Z.; Wang, Y.; Liu, Q. Manganese-Catalyzed Upgrading of Ethanol into 1-Butanol. J. Am. Chem. Soc. 2017,
139 (34), 11941-11948. https://doi.org/10.1021/jacs.7b05939.

Tondreau, A. M.; Boncella, J. M. 1,2-Addition of Formic or Oxalic Acid to $-\mathrm{N}\{\mathrm{CH} 2 \mathrm{CH} 2(\mathrm{PiPr} 2)\} 2$-Supported $\mathrm{Mn}(\mathrm{I})$ Dicarbonyl Complexes and the Manganese-Mediated Decomposition of Formic Acid. Organometallics 2016, 35 (12), 2049-2052. https://doi.org/10.1021/acs.organomet.6b00274.

(44) Wei, Z.; de Aguirre, A.; Junge, K.; Beller, M.; Jiao, H. Exploring the Mechanisms of Aqueous Methanol Dehydrogenation Catalyzed by Defined PNP Mn and Re Pincer Complexes under Base-Free as Well as Strong Base Conditions. Catal. Sci. Technol. 2018, 8 (14), 3649-3665. https://doi.org/10.1039/C8CY00746B.

(45) Luque-Urrutia, J. A.; Pèlachs, T.; Solà, M.; Poater, A. DoubleCarrousel Mechanism for Mn-Catalyzed Dehydrogenative Amide Synthesis from Alcohols and Amines. ACS Catal. 2021, 11 (10), 6155-6161. https://doi.org/10.1021/acscatal.1c00693.

(46) Kumar, A.; Espinosa-Jalapa, N. A.; Leitus, G.; Diskin-Posner, Y.; Avram, L.; Milstein, D. Direct Synthesis of Amides by Dehydrogenative Coupling of Amines with Either Alcohols or Esters: Manganese Pincer Complex as Catalyst. Angew. Chem. Int. $\quad$ Ed. 2017, $56 \quad$ (47), 14992-14996. https://doi.org/https://doi.org/10.1002/anie.201709180. 


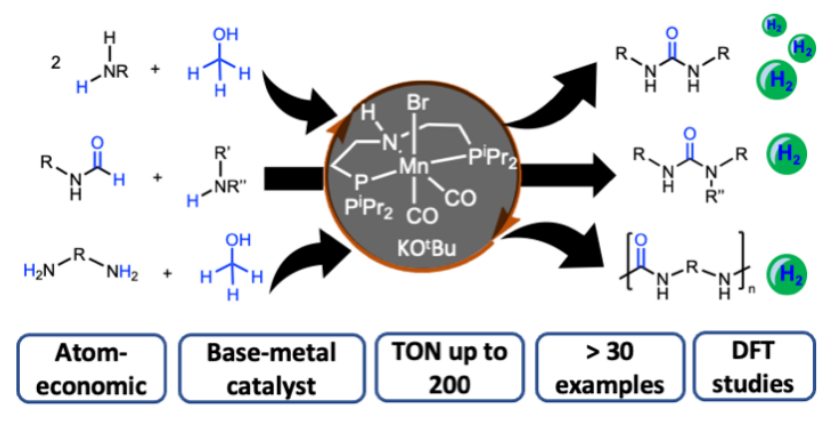

